\title{
Inadecuado uso del símbolo de la medicina en el Perú: ¿Vara de Esculapio o Caduceo?
}

Inadequate use of the medical emblem in Peru: Rod of Asclepius or Caduceus?

\section{Sr. Editor:}

En Perú es frecuente observar que muchas instituciones relacionadas con la salud utilizan emblemas que los representan, pero nos hemos percatado que muchos de estos símbolos no están relacionados con la salud ni la medicina, posiblemente por desconocer su historia o su significado.

El símbolo de la Medicina usada actualmente es una vara con una serpiente enroscada (símbolo de Esculapio) que fue oficializada el año 1948 por la Organización Mundial de la Salud (OMS)(1), el origen de este símbolo se remonta a la historia de Esculapio, Dios de la Medicina, conocido como Asclepios para los griegos y Esculapio para los romanos (2); la historia cuenta que cuando Esculapio visitaba a uno de sus pacientes, una serpiente se enredó en su bastón y al darse cuenta la mató, poco tiempo después apareció otra serpiente con hojas de una planta en su boca y se las dio a la serpiente muerta, que la volvió a la vida de inmediato, Esculapio tomó algunas de estas hojas y las utilizó para curar; este incidente generó el símbolo del ejercicio médico: una serpiente enroscada alrededor de una rama (3) (Figura 1A).

Muchas veces el símbolo de la Medicina es confundido con uno muy parecido, el caduceo de Hermes o Mercurio, Dios del comercio para los griegos, que consta de una rama de olivo y dos hebras de lana las que sucesivamente fueron sustituidas por dos cintas blancas y luego por dos serpientes, que en la
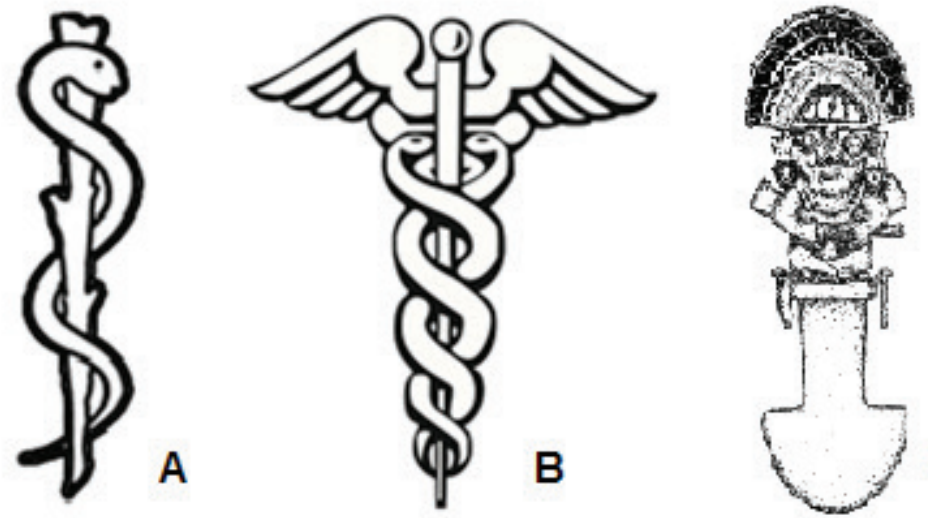

C

Figura 1. Imágenes de diferentes representaciones culturales A: Vara de Esculapio; B: Caduceo de Hermes o Mercurio; C: Tumi o cuchillo ceremonial

\footnotetext{
1 Escuela de Medicina, Universidad Nacional de San Antonio Abad del Cusco. Cusco, Perú.

Escuela de Medicina Humana, Universidad Continental. Huancayo, Perú.

Estudiante de Medicina ;

Médico Cirujano
} 

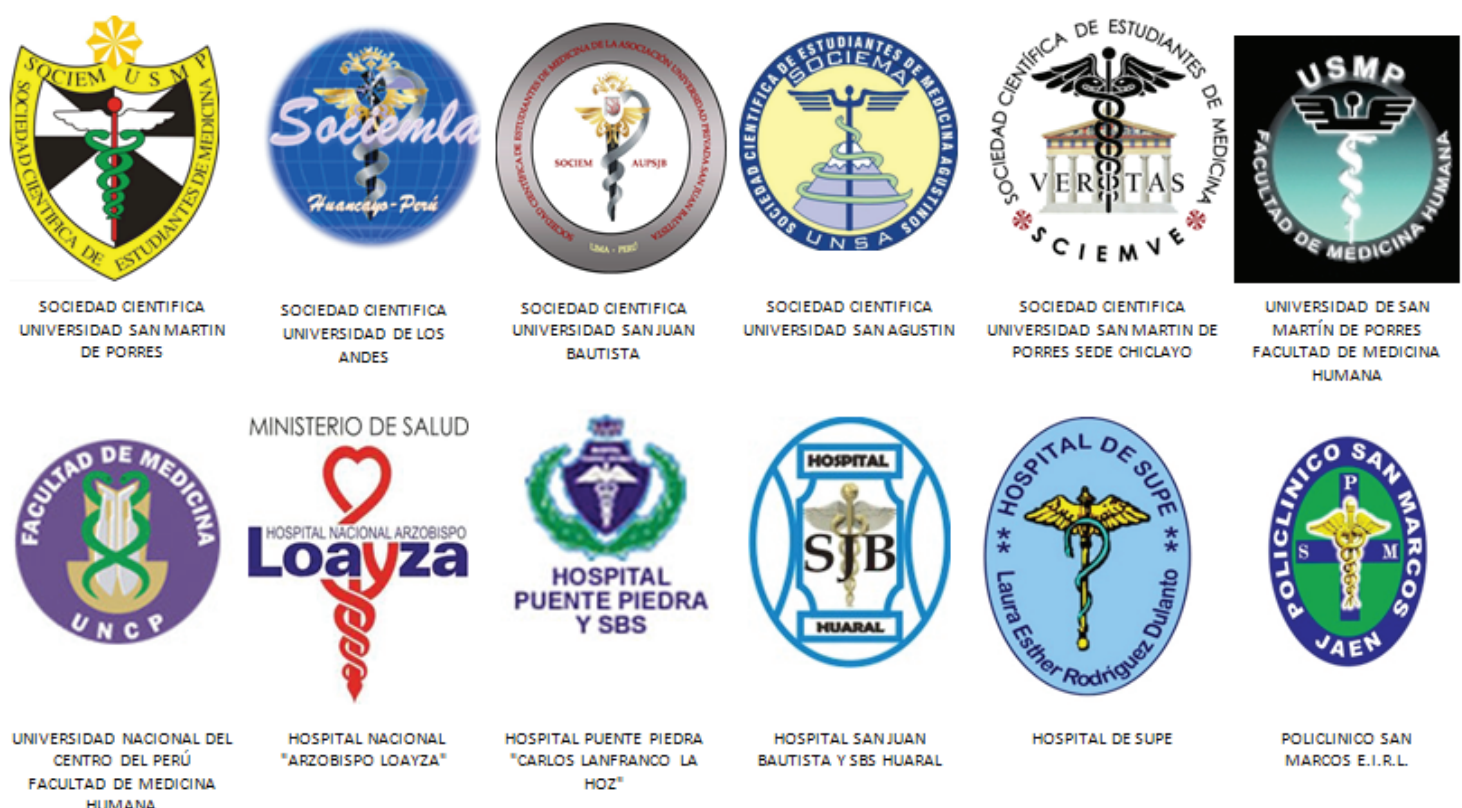

HOSPITAL NACIONAL "ARZOBISPO LOAYZA"

HOSPITAL PUENTE PIEDRA HOSPITAL SAN JUAN HOZ

BAUTISTA YSBS HUARAL

HOSPITAL DE SUPE

POLICLINICO SAN MARCOS E.I.R.L.

Figura 2. Logos de instituciones peruanas relacionadas a la salud que utilizan el Caduceo de Hermes como símbolo.

parte superior se miran y están enlazadas en un bastón que expresa el poder, además consta de dos alas que usaba Hermes para protegerse de la lluvia (Figura 1B) (4).

Si bien la OMS adoptó la vara de Esculapio como símbolo de la práctica médica, en el Perú a veces es erróneamente utilizado por algunas instituciones dedicadas a la salud, quienes la confunden con el caduceo de Hermes que representa el comercio (Figura 2). Además siendo la vara de esculapio una representación de la cultura Greco-Romana, se sugiere que las instituciones peruanas utilicen emblemas relacionados con la cultura peruana, como lo hace la institución representativa de todos los médicos peruanos, el Colegio Médico del Perú que utiliza el Tumi o cuchillo ceremonial (Figura 1C), que era usado para la realización de trepanaciones craneanas y otras cirugías propio del antiguo Perú (5).

\section{Giuston Mendoza-Chuctaya ${ }^{1, a}$, Reneé Montesinos-Segura ${ }^{1, a}$, Christian R. Mejia ${ }^{2, b}$}

\section{Correspondencia:}

Giuston Mendoza Chuctaya

APV Praderas del Inca B-5- San Sebastián, Cusco -

Perú.

Correo electrónico: giustonmch@gmail.com

Teléfono: 51984040426

\section{REFERENCIAS BIBLIOGRÁFICAS}

1. Organización Mundial de la Salud. El emblema de la OMS. Ginebra: Organización Mundial de la Salud (Citado el 03 de noviembre 2016). Disponible en: http://www.who.int/about/licensing/emblem/es/

2.Pérez-Vazquez, IA, Sánchez-Lera RM. El bastón de Esculapio: su historia. Human Méd. 2014;14(1): 0-0. (Citado el 03 de noviembre 2016). Disponible en: http://www.humanidadesmedicas.sld.cu/index.php/ $\mathrm{hm} /$ article/view/479/350

3. Garrocho C. La serpiente de Asclepios. Rev Mex Patol Clin. 2010; 57(3):154-155.

4. Mercurio DH, Murillo-godínez G. Artículo de opinión el símbolo de la medicina: la vara de esculapio (asclepio) o el caduceo de Hermes (Mercurio). Med Int Mex. 2010; 26(6):608-15.

5.Galán-Rodas E, Laberiano C, Maguiña C. Historia del tumi: símbolo de la medicina peruana y del Colegio Médico del Perú. Acta méd peru. 2012; 29(1):56-8. 